\title{
Insights into energy requirements in disease
}

\author{
Marinos Elia* \\ Institute of Human Nutrition, University of Southampton, Southampton General Hospital, Mailpoint 113 , \\ Tremona Road, Southampton SO 16 6YD, UK
}

\begin{abstract}
Accurate information about the energy needs of a range of acute and chronic diseases and morbidity is lacking and often complicated by the medication prescribed to treat the condition and also because of the presence of pre-existing malnutrition. Assessing the energy requirements of patients with acute and chronic diseases is more complex than for those in good health. These requirements not only depend on the aggressiveness of the disease and level of inactivity it causes, but also on the treatment, and the presence of prior malnutrition. It used to be generally believed that the energy requirements were increased in a number of diseases. It is now realised that this is not usually the case. Therefore, it is necessary to put these changing ideas into context by considering a wide range of acute and chronic diseases which this paper proposes to do. This paper is almost exclusively restricted to studies that have measured total energy expenditure (TEE) using tracer techniques in both hospital and the community (mostly doubly labelled water and to a lesser extent bicarbonateurea), and continuous 24-hour indirect calorimetry in artificially ventilated patients in hospital.
\end{abstract}

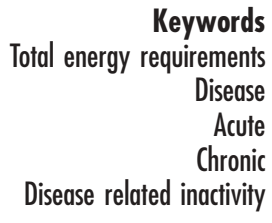

\section{Introduction}

Despite the immense global burden of disease, there is little accurate information about the energy requirements of patients suffering from a variety of common diseases, such as degenerative conditions producing arthritis, angina, poor eyesight and hearing, and infective conditions, producing diarrhoeal diseases, malaria, other tropical diseases and infestations and tuberculosis which is associated with acquired immune deficiency syndrome (AIDS). Furthermore although several studies have used tracer techniques to measure total energy expenditure (TEE) in patients infected with the human immunodeficiency virus $(\mathrm{HIV})^{1-6}$ they have been undertaken in developed countries where the course of the disease may differ substantially from that in less well developed countries, not only because of the absence of 'expensive' new treatments such as anti-protease inhibitors but also because of the presence of pre-existing malnutrition and other diseases.

There is a continuum in physical function between health and disease, but the dividing line between them can be difficult to define. For example in the UK more than four out of 10 subjects aged over 65 years have longstanding health problems that limit physical activity ${ }^{7}$. Less severe disabilities may produce effects on physical activity that are difficult to distinguish from normal activity. Indeed, it seems that the prevalence of disease is so common in older subjects that it is difficult to define 'normal', especially in extreme old age. At the other extreme of the life span, young children in developing countries, who are frequently growth retarded, may have evidence of an acute phase inflammatory response without overt signs of disease ${ }^{8}$. Furthermore, if dietary recommendations are provided for healthy normal weight individuals, and not for overweight/obese individuals, or underweight individuals, who frequently suffer from disease-related malnutrition, then more than half of the population of many countries will be excluded.

Assessing the energy requirements of patients with acute and chronic diseases is more complex than for those in good health. These requirements not only depend on the aggressiveness of the disease and level of inactivity it causes, but also on the treatment, and the presence of prior malnutrition. It used to be thought that the energy requirements of a number of severe acute diseases were increased $^{9,10}$. It also used to be thought that the energy requirements of individuals with spastic disorders, such as spastic cerebral palsy ${ }^{11,12}$, were increased. Now it is realised that this is not usually the case. Therefore, it is necessary to put these changing ideas into context by considering a wide range of acute and chronic diseases. The purpose of this paper is threefold:

- to highlight some of the principles involved in estimating energy requirements in disease, especially those that differ or do not apply to health;

- to review studies of TEE in patients with disease; 
- to assess the limits of human physical activity, ranging from disease related inactivity at one extreme to severe physical exertion at the other extreme and to briefly consider the energy needs associated with a moderate increase in physical activity in inactive or moderately active subjects.

This paper is almost exclusively restricted to studies that have measured TEE directly using tracer techniques in both hospital and the community (mostly doubly labelled water and to a lesser extent bicarbonate-urea ${ }^{2,13-15}$ ), and continuous 24-hour indirect calorimetry in artificially ventilated patients in hospital. Although other instruments, such as accelerometers and heart rate monitors have been used to estimate TEE in free living conditions in disease, they are less accurate ${ }^{16-19}$. Factorial methods, which take into account the energy cost of specific physical activities, have also been used in patients with disease ${ }^{14,20-22}$, although the type of activities and their energy cost may differ from health ${ }^{22}$.

\section{Principles and methodological issues}

The energy requirements of sick people are greatly influenced by the type (acute or chronic), severity, and phase of the disease (acute or recovery phase). They are also affected by the presence of other physical and psychological disabilities, which may vary over time, and the nutritional state of the patient. Sometimes it may not be appropriate to treat the disease or the associated malnutrition, as when a patient is approaching death and feeding is a burden. There are also a number of situations, where provision of nutritional therapy is controversial. Is it appropriate to attempt to feed or improve the nutritional state of malnourished patients with severe end stage dementia, who stop eating? Is it appropriate to improve the growth of children with severe cerebral palsy, when the increase in weight is likely to prevent the mother from carrying them, making care more difficult? It has even been suggested that in some situations it may be preferable to maintain rather than correct a poor protein-energy state. For example, it has been argued that a large increase in body weight in some patients with heart failure, may aggravate or precipitate heart failure and increase the severity of symptoms, whereas a low body weight may reduce the load to the heart so that cardiac symptoms are kept under control.

A number of specific issues relating to measurement and interpretation of energy intake and expenditure in disease are detailed below.

\section{Energy intake}

Subjects with disease may be in substantial energy imbalance for days, weeks, and sometimes months. This imbalance is often caused by anorexia, which is a common consequence of traumatic, infective, malignant or other inflammatory diseases. It is obvious that accurate measurements of energy intake in disease do not necessarily reflect the energy required to maintain energy balance or the energy required to achieve optimal health. Furthermore, although in undernourished subjects, additional energy is required for repletion and improvement in tissue function, health and well being, the reverse applies to obese individuals.

The timing of nutritional support is also important. For example, aggressive overfeeding in the acute phase of injury can cause metabolic disturbances, such as hyperglycaemia (diabetes of injury) and increased $\mathrm{CO}_{2}$ production, which can be detrimental to patients with respiratory failure. Hyperglycaemia has also been reported to worsen a stroke in animal models of cerebral ischaemia ${ }^{23}$, and in animal models of sepsis an increase in the amount of feeding, even within the submaintenance range, increases mortality ${ }^{9,24}$. Similarly, aggressive overfeeding of severely malnourished individuals, especially those recovering from disease, can cause sudden death from the re-feeding syndrome, which is associated with low circulating concentrations of potassium, magnesium and phosphate ${ }^{25,26}$. In contrast, very slow repletion during recovery can prolong the period of ill health, as well as poor work performance and poor quality of life. Finally, nutritional intake in disease may differ from health in that it can be provided artificially using an enteral tube or venous catheter (sometimes for life), independent of the appetite.

\section{Energy expenditure}

\section{Basal metabolic rate}

Estimation of BMR. Basal metabolic rate (BMR), which forms the basis of the factorial method to estimate TEE, is more variable in disease than in health. Apart from being influenced by the type, severity, and phase of the illness (see Fig. 1), BMR is also influenced by the nutritional status of the patient and a wide range of treatments, which may vary from surgical interventions, immobilisation, and artificial ventilation to blood transfusions and drug therapy. For example, drugs such as catecholamine increase BMR, while morphine and barbiturates can decrease it. Other drugs limit physical activity by causing sedation, drowsiness or even paralysis so that patients can comply with artificial ventilation. Standard reference tables or equations for predicting BMR from weight, height and age, were established for use in healthy subjects without malnutrition and disease, and without dehydration and oedema, which can have substantial effects on body weight. Therefore, prediction of BMR is more likely to be in error in disease than in health.

Measurement of BMR. Measurement of BMR may be difficult or impossible to establish in individuals with muscular spasms or twitching, and those fed continuously by artificial nutrition, which prevents the overnight fasted 


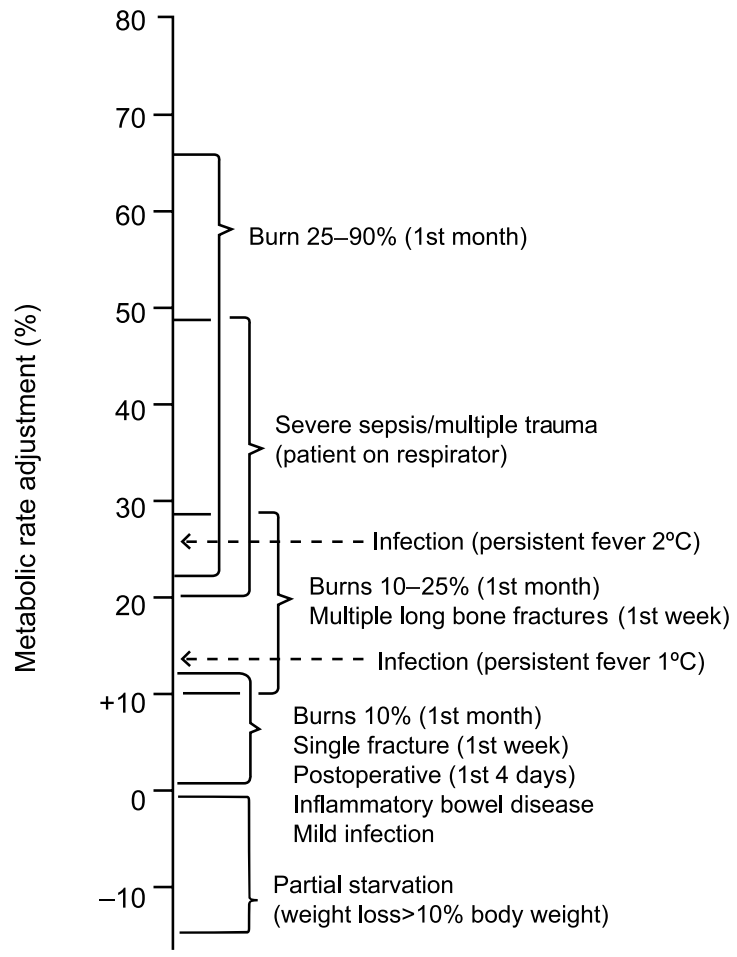

Fig. 1 Approximate increase in BMR produced by acute diseases. The time after the onset of the disease is indicated (based on Elia ${ }^{95}$ )

state from being established. Resting energy expenditure (REE) in patients being fed in this manner is higher than normal BMR, in proportion to the magnitude of dietaryinduced thermogenesis. This in turn depends on the rate of feeding and the composition of the feed. Furthermore, although BMR by definition is measured in an awake, relaxed and overnight fasted state, patients with disease may be anxious, unconscious, confused, sedated, or paralysed. Measurements of REE in patients being ventilated pose their own problems. For example, a given percent error in measuring high concentrations of oxygen can produce several-fold greater errors in calculated energy expenditure, than at lower oxygen concentrations ${ }^{27}$.

Estimating TEE from BMR (or REE). There is very limited information about the energy cost of physical activity in disease $\mathrm{e}^{21,22}$. Royall et $\mathrm{al}^{22}$ estimated the energy cost of various physical activities in burn patients requiring ventilation. These activities, which include position change, suctioning, physiotherapy, face/mouth care, family visit, and dressing, increase REE between 0 and $42 \%$ above baseline (night and morning) REE. Similar information exists for other activities undertaken by preoperative ambulatory patients ${ }^{28}$. The energy cost of sitting, standing and walking in hospital at a rate of 1.2$1.5 \mathrm{miles} / \mathrm{h}$ was found to be 7,17 and $145 \%$ greater than REE, respectively. However, TEE expressed as multiples of BMR may give misleading information about the energy cost of physical activity, especially when BMR is markedly increased by acute disease. Furthermore, it is obvious that the efficiency with which physical activities are performed can be reduced by spastic conditions, such as Parkinson's disease, Huntington's chorea, and cerebral palsy. Arthritis, pain, and deformities are also expected to reduce the efficiency of undertaking specific physical tasks, especially when the natural movements are disturbed. However, quantitative information in this area is sparse.

\section{Total energy expenditure (TEE)}

Measurements of TEE. TEE in patients with disease can be measured by continuous indirect calorimetry or tracer methods, all of which can be regarded as reference methods. Other methods are also available (activity monitors, heart rate monitoring), although there have been few attempts to validate them in different pathological states ${ }^{16,29}$.

Interpretation. Whether measurements of TEE (or measurements of BMR) are regarded as normal or abnormal, relative to a healthy group, may depend on the way in which the results are expressed. This can be problematic for patients with disease with abnormal body composition and body proportions, who preferentially lose or preserve particular tissues or organs (e.g. muscle wasting in certain neurological conditions). Elia ${ }^{30}$ summarised over 20 indices that have been used by different workers to express energy expenditure (BMR), including absolute EE, EE per kilogram body weight, EE per kilogram fat free mass (FFM), EE per $\mathrm{m}^{2}$. In children these have also been expressed as a percentage of values obtained in healthy children of the same age or same surface area or same height. In infants with growth failure, both the BMR of the body and the tissue specific BMR may be reduced, while $\mathrm{BMR} \mathrm{kg}{ }^{-1}$ body weight may be increased due to preferential preservation of the brain, which has a high metabolic rate ${ }^{30}$. Similarly, TEE may be low when expressed in relation to values obtained in children of the same age, and normal when it is expressed in relation to healthy children of the same weight. TEE may also be expressed as a ratio to BMR (physical activity level or PAL) in an attempt to overcome some of the difficulties associated with comparisons of individuals of different body weight. However, the hypermetabolic effect of disease and the hypometabolic effect of weight loss alter BMR to a greater extent than in health, even when age, weight and height are taken into account ${ }^{31}$. Therefore, PAL values based on measured BMR and predicted BMR (based on values established for healthy subjects) can vary widely, especially in acute disease, which typically increases BMR.

Need to change energy balance. As with energy intake, energy expenditure does not necessarily indicate the requirements of the undernourished patient who is in need of repletion, or the requirements of the over- 
nourished patient, who is in need of depletion of excess fat.

Although direct measurements of TEE are rarely undertaken in routine clinical practice, they have helped establish important concepts about energy requirements in disease. Some of the practical and theoretical principles of assessment of energy requirements in pathological states can be appreciated by considering the simultaneous changes in BMR, physical activity and TEE produced by acute and chronic diseases and the ways in which some of them are calculated.

\section{Acute and chronic diseases}

The figures and tables in this section (Figs. 2-5; Tables 1 and 2) are used to illustrate the effects of different acute and chronic diseases on components of energy turnover. For patients with chronic disease, who are weight stable, energy expenditure due to physical activity (EEPA) was calculated using the following equation:

$$
\mathrm{EEPA}=\mathrm{TEE}-0.1 \mathrm{TEE}-\mathrm{BMR}=0.9 \mathrm{TEE}-\mathrm{BMR}
$$

where 0.1TEE is assumed to represent thermogenesis (predominantly dietary induced thermogenesis), and BMR, basal metabolic rate. When there is energy balance, thermogenesis is also equal to about $\times 0.1$ energy intake, but the value of 0.1TEE was usually used in the equation because measurement of TEE by tracer methods in free living conditions over periods of 1-2 weeks were considered to be more accurate than measurements of energy intake (EI). However, in patients who are in substantial energy imbalance, such as those losing weight rapidly due to inadequate dietary intake (e.g. see HIV, rapid weight loss group in Table 1), EEPA was calculated using the following equation, which incorporates the term $0.1 \mathrm{EI}$ :

$$
\mathrm{EEPA}=\mathrm{TEE}-0.1 \mathrm{EI}-\mathrm{BMR}
$$

For acute diseases, where continuous energy intake is provided while measurements of gaseous exchange were made, energy expenditure at rest is referred to as REE to

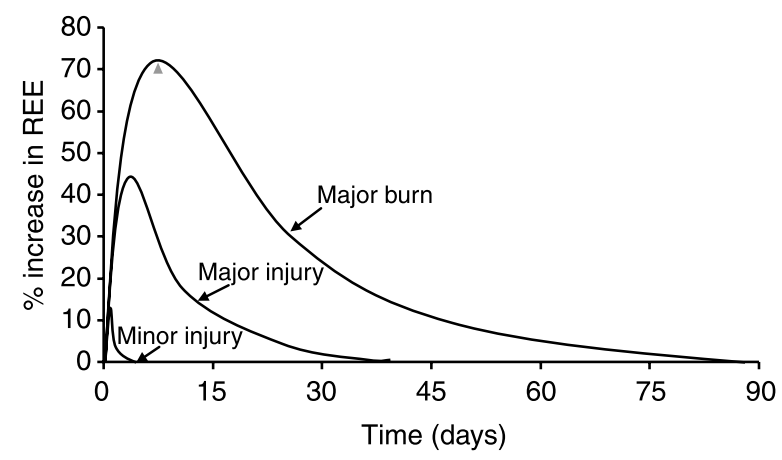

Fig. 2 Approximate time course of BMR changes after minor injury, major injury, and extensive burns (from Elia ${ }^{38}$ ) distinguish it from BMR, which is measured at rest in the post absorptive state (overnight fasted state).

For comparison of results with healthy individuals, most studies have included a control group involving a small number of subjects. For an overall comparison of different studies, use was made of 559 measurements of doubly labelled water involving healthy subjects aged 13 to over 75 years (259 males and 301 females) ${ }^{32}$.

\section{Diseases in adults}

This section illustrates that both TEE and the energy requirements of many diseases are decreased, mainly because of a reduction in EEPA. This reduction in EEPA can occur because disease produces lethargy and restricts physical activity (e.g. pain due to claudication - angina and arthritis are expected to do the same). It also occurs because treatment, especially in hospital, usually requires restricted physical activity. Loss of weight will contribute to the reduction in TEE, partly because it reduces the energy expended in physical activity, and partly because it reduces BMR. In most of the chronic conditions examined in this paper, BMR adjusted for weight is usually normal or slightly increased $(\sim 10 \%)$, while in most acute conditions it is usually increased $(0-50 \%$ and occasionally more). This increase in BMR is counteracted by the decrease in EEPA, with the overall result that TEE is usually normal or decreased. More severe acute disease produces greater increments in BMR and greater reductions in EEPA.

\section{Chronic diseases in adults}

Most of the studies on TEE in chronic diseases have been undertaken in high income countries, rather than low income countries, which bear most of the worldwide burden of infectious diseases, including HIV/AIDS. Although BMR has generally been reported to be normal or increased in patients infected with HIV, tracer studies suggest no increase in TEE. One of these ${ }^{1}$ reported that in subjects who had lost weight because of active disease, TEE and EEPA were reduced. The weight stable patients did not have reduced TEE or EEPA. Another study ${ }^{3}$ selected HIV positive men on the basis of weight stability for the previous 3 months $(<1.5 \mathrm{~kg}$ weight change), absence of opportunistic infections, and no change in the time spent on sports and type of employment in the previous 2 years. It reported that 'BMR' was elevated ( $\sim 9 \%)$ but neither TEE or EEPA were significantly different from a control group. In contrast, a preliminary report involving patients with stable disease ${ }^{4}$ reported a reduced PAL ratio (TEE/BMR) compared to the control group. A further study involving subjects with more advanced disease $(80 \% \text { with AIDS - stage IV disease) })^{33}$, found that BMR was elevated by $5 \%$, while TEE and PAL (1.42 \pm 0.14$)$ were reduced compared to a reference population. Overall, it can be concluded that patients with early disease tend to have normal EEPA and TEE, while those 


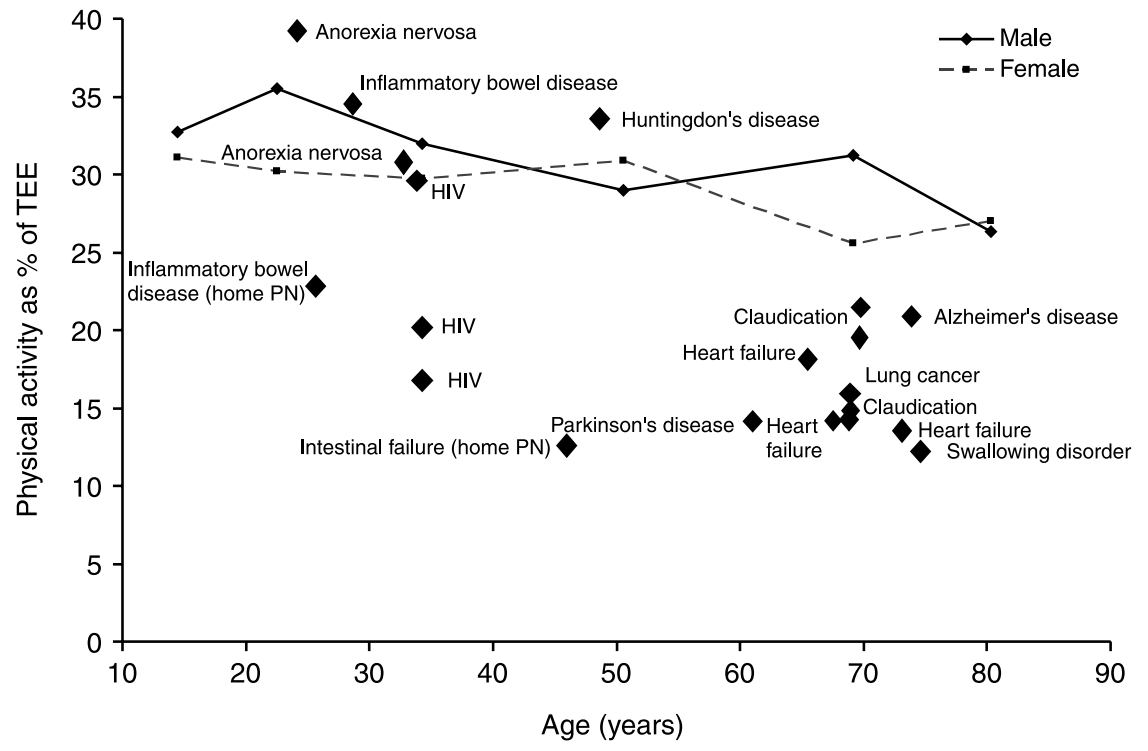

Fig. 3 The contribution of physical activity to TEE in adult patients with chronic diseases. IBD represents inflammatory bowel disease, HPN, home parenteral nutrition, and Huntington's and Parkinson's refer to Huntington's and Parkinson's diseases

with more advanced disease and weight loss have reduced EEPA and TEE.

A study ${ }^{34}$ on the effects of treating mild giardiasis in Mexican children showed no change in BMR and a nonsignificant change in PAL (from $1.37 \pm 0.2$ to 1.54 ). This is not surprising because the children had not lost weight or appetite, and were well nourished. Another study in adult patients with melioidosis in South East Asia ${ }^{15}$ showed an increase in BMR but not in TEE. As a result of this and studies on protein metabolism in melioidosis it was concluded that reduced energy intake was likely to be the prime cause of wasting ${ }^{15}$.

Virtually all other tracer studies for measuring energy expenditure in adults with chronic diseases have been undertaken in developed countries. It is not surprising that many of these have involved the elderly, who are more likely to suffer from chronic disorders, such as claudica-

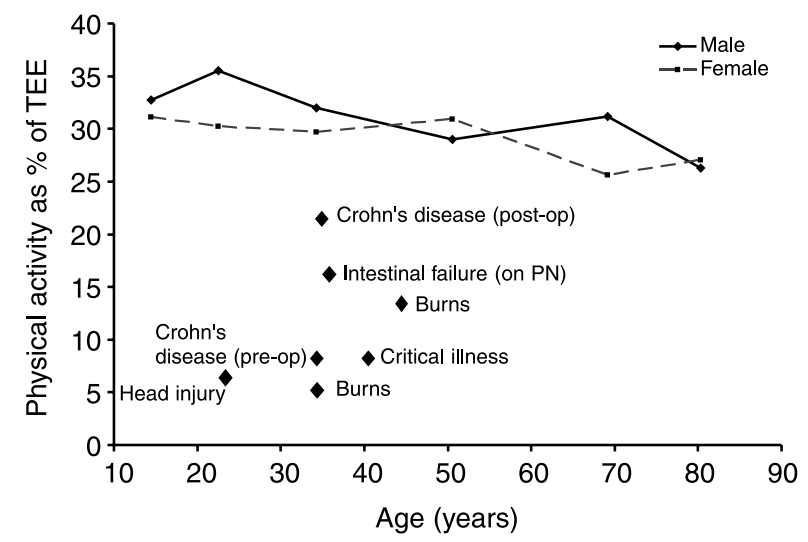

Fig. 4 The contribution of physical activity to TEE in adult patients with acute diseases. The figure was based on Table 2 and values of TEE obtained by doubly labelled water in healthy free living subjects in developed countries, which are represented by the solid and dashed lines (based on Elia et al. ${ }^{38}$ ) tion, cancer, and Parkinson's disease (Table 1). In degenerative conditions (e.g. atherosclerosis leading to claudication), BMR is usually normal, whereas TEE and PAL are often significantly decreased. This decrease in TEE also implies that energy intake is also decreased. In spastic disorders or those associated with involuntary movements, such as Parkinsons's disease, TEE was not found to be increased, because of a reduction in the energy expended in voluntary physical activity (Table 1). A similar situation has been reported in girls with Rett syndrome (see below), and adults with Huntington's chorea (Table 1).

Although tracer techniques that measure TEE have had limited application in patients with malignant disorders, a study of patients with lung cancer showed a significant

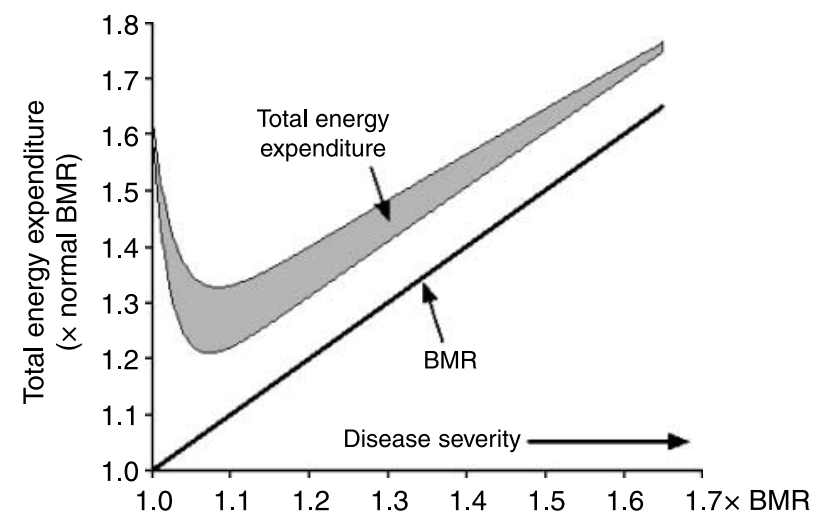

Fig. 5 The effect of acute disease on BMR and TEE expressed as multiples of normal BMR in health. Mean values for TEE/BMR in groups of healthy subjects ranging from young to old are 1.551.80. The figure was constructed using Fig. 1 and estimates of TEE obtained from a combination of factorial, tracer and indirect calorimetric methods (see text) 
increase in BMR and a reduction in TEE, again as a result of reduced physical activity. Such conclusions in patients with lung cancer are supported by studies involving accelerometers ${ }^{17}$.

Table 1 and Fig. 3 summarise the overall effects of chronic diseases on energy expenditure, and generally show that TEE is normal or decreased. In those with advanced disease or disease-related weight loss, both EEPA and TEE are usually decreased, despite a possible increase in BMR. The weight loss that may occur in such diseases is more likely to be due to a decrease in energy intake than an increase in energy expenditure. A possible exception to this general rule concerns subgroups of patients with anorexia nervosa, who have been reported to have increased EEPA and TEE, when adjusted for weight $^{35}$. However, some studies of women with anorexia nervosa show no increase in TEE, after adjustment for weight $^{36}$ (Table 1). When no adjustment for weight is made, TEE (MJ day ${ }^{-1}$ ) is likely to be lower than in healthy women of the same age.

The above results are consistent with clinical observations. It is well known that energy levels and lethargy progressively deteriorate with more advanced malignant, infective and degenerative diseases. It is also known that some patients with anorexia nervosa remain relatively active in order to maintain a low body weight.

\section{Acute diseases in adults}

Acute diseases increase REE above that predicted for healthy individuals of the same age weight and height by up to $100 \%^{37}$, although usually $0-40 \%$ (Fig. 1). Both the magnitude and duration of the increase are dependent on the severity of disease (Figs. 1 and 2). The effect of 'injury' on BMR is also influenced by age. For example the increase in BMR after surgery may last a few days after elective surgery in adults and only a few hours in infants ${ }^{38}$. Acute or sub-acute diseases usually cause a decrease in lean body mass. Therefore, after the early phase of an illness BMR may decline below pre-illness BMR before beginning to return to normal in the recovery phase.

Although it used to be thought that the energy requirements of acute diseases were increased, concepts gradually changed over the last $2-3$ decades for a variety of reasons. It was realised that peak BMR was often measured and inappropriately extrapolated to a much longer period of time. Many measurements were also made while the patients were being fed, with the result that dietary induced thermogenesis was erroneously attributed to the hypermetabolic effect of disease. Furthermore, although stress factors due to disease took into account the rise in body temperature, this rise was sometimes doubly accounted, so that BMR was overestimated by $13 \%$ per ${ }^{\circ} \mathrm{C}$ rise in body temperature. Finally, changes in the management of a number of diseases, including burns, have reduced morbidity and improved the rate of recovery, and at the same time reduced the magnitude and duration of hypermetabolic state $e^{9,10}$.

Table 2 summarises the results of TEE measured by the doubly labelled water method or by continuous indirect calorimetry, which has been applied to bed-bound artificially ventilated patients, e.g. those with head injuries or other critical illness. Although BMR is frequently increased, TEE is usually not elevated, mainly because of the associated reduction in physical activity (Figs 4 and 5). The overall result is that TEE is normal or even decreased compared to values obtained in healthy subjects in free living circumstances. Except for the most severe acute diseases, such as burns, when TEE may be transiently elevated above normal ${ }^{37}$, TEE is normal or reduced compared to normal free-living conditions (Fig. 4). Even patients with critical illnesses in intensive care units (mean body weight of $70 \mathrm{~kg}$ ) typically have a TEE of only about $1700-2300 \mathrm{kcal} \mathrm{day}^{-1}$. Figure 4 shows the effect of various acute diseases in reducing TEE relative to the mean values obtained in healthy free-living subjects. The conclusions are also supported by estimates of TEE using the factorial method. For example, activity in pre-operative patients was found to account for approximately 20\% of resting values. It was reduced to $5 \%$ during the first four postoperative days, $10 \%$ during days $5-8$, and $15 \%$ during days $9-12^{28}$. In critical illness the values are often $<10 \%$ of REE and TEE (Fig. 4, Table 2).

\section{Diseases in children}

Assessment of the energy requirements of children is more difficult than in adults because of the need to consider growth and appropriate ways of expressing energy expenditure. The section below addresses some of these difficulties, and at the same time illustrates some overarching concepts of the effects of acute and chronic diseases' energy expenditure, which apply to both children and adults. In particular they illustrate the effect of disease in reducing EEPA and TEE, which can be striking in children who are underweight, even after making adjustments for weight.

\section{Chronic diseases in children}

A doubly labelled water study on energy turnover ${ }^{6}$ was carried out in $23 \mathrm{HIV}$ infected children (8M, 15F; 11 with growth failure) aged 1.3-13.3 years. Energy intake, and not energy expenditure, was reduced when compared to expected normal values for age and gender. Another study $^{5}$ involved 37 HIV infected children, 16 of whom had reduced growth rates and 21 did not (1.1. \pm 1.2 vs. $6.6 \pm 1.1 \mathrm{~cm} /$ year). The mean weight of the two groups was similar $(23.1$ vs. $23.5 \mathrm{~kg})$ but the growth retarded group was older ( 8.3 vs. 6.5 years; $P<0.016$ ). Age adjusted TEE tended to be lower in the growth failure group (NS), but REE was similar to the control values, after adjusting for age and FFM. The viral load was inversely 


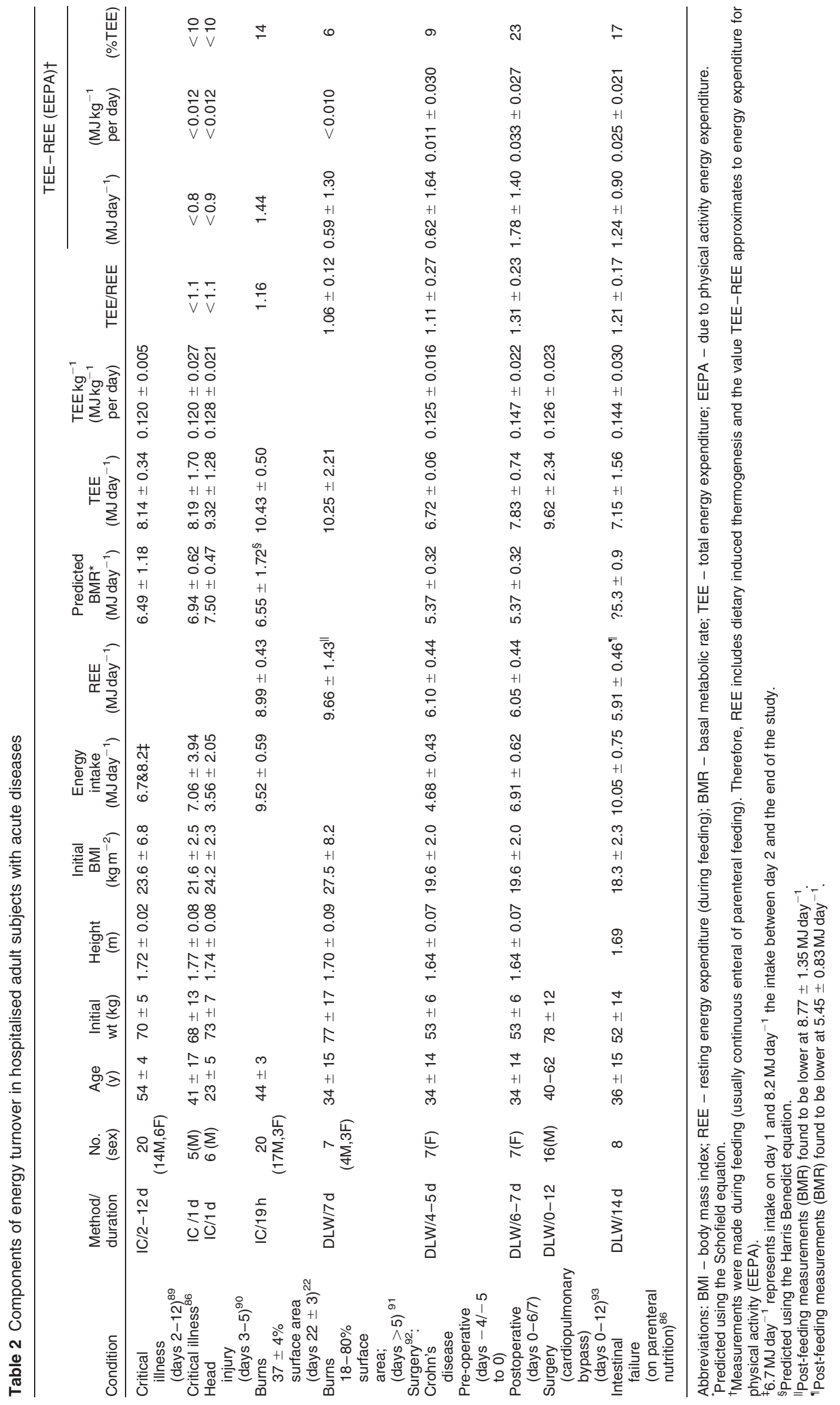


related to FFM, growth velocity and energy intake. Since energy intake, and not TEE, was significantly reduced in growth failure (5.64 vs. $8.31 \mathrm{MJ} \mathrm{day}^{-1}$ ), the authors concluded that energy intake may not be adequate to support the development of FFM. The reduction in energy intake rather than an increase in TEE, is analogous to the situation in adults with active disease and weight loss, which were discussed above $e^{1,2}$.

Several studies have examined the effect of cerebral palsy on $\mathrm{TEE}^{19,20,39}$. One of these ${ }^{19}$ involved nine children (5M, 4F; six spastic diplegia and three spastic tetraplegia) with a mean age of 10.7 years, weight $38.6 \mathrm{~kg}$, and BMI 19 . $6 \mathrm{~kg} \mathrm{~m}^{-2}$. Mean TEE was only $7.4 \mathrm{MJ} \mathrm{day}^{-1}\left(\sim 0.19 \mathrm{MJ} \mathrm{kg}^{-1}\right.$ per day), and so the ratio of TEE/'REE' was also reduced at 1.28. Although the spastic condition may elevate 'REE', predicted BMR using the $\mathrm{FAO} / \mathrm{WHO} / \mathrm{UNU}$ equation (based on mean weight of the group) is within 10\% of 'REE'. Therefore, it is reasonable to conclude that TEE in this group of children was reduced, predominantly because of a reduction in voluntary activity. Another study involving children aged 15-20 years came to a similar conclusion, but it also analysed the results according to ambulation ${ }^{20}$. For the group as a whole TEE and TEE kg ${ }^{-1}$ were significantly reduced (REE was $103 \%$ of the BMR predicted by the FAO/WHO/UNU) ${ }^{40}$. The non-ambulatory group had a significantly lower TEE/ REE (1.23) than the ambulatory group (1.79) and the control group of subjects (1.76). Despite greater spasticity in the ambulatory patients, voluntary physical activity was disproportionately reduced so that total EEPA was reduced. Such findings are confirmed by studies in adult patients with cerebral palsy (estimated EEPA, 16\% (nonambulatory patients) vs. 25\% of TEE (ambulatory patients $)^{41}$. The largest study ${ }^{39}$ on TEE in patients with cerebral palsy involved 61 children with spastic quadriplegia and growth retardation (mean age, 10.3 years and weight $18.8 \mathrm{~kg}$ ( $Z$-score -2.5$)$ ). REE was $91 \%$ of the BMR predicted by the FAO/WHO/UNU equation ${ }^{40}$. TEE, TEE/ REE and TEE $\mathrm{kg}^{-1}$ were all significantly lower than those obtained in a younger group of control subjects with a mean age of 6.2 years and mean weight, $22 \mathrm{~kg}$ ( $4.03 \mathrm{vs}$. $6.93 \mathrm{MJ} \mathrm{day}^{-1}$; 1.23 vs. 1.57 ; and 0.21 vs. $0.31 \mathrm{MJ} \mathrm{kg}^{-1}$ per day, respectively). The overall conclusions emerging from these studies do not support earlier suggestions of high energy requirements in cerebral palsy ${ }^{11,12}$. Difficulties with eating and swallowing are probably major causes of growth failure in this population of subjects.

One of the first studies of TEE in cystic fibrosis ${ }^{42}$ involved nine children $(4 \mathrm{M}, 5 \mathrm{~F})$ aged $0.7-2$ years. TEE $\mathrm{kg}^{-1}$, but not TEE, was significantly increased compared to age and age plus weight matched control subjects (no indication of sex matching). Measurements of BMR were not made in this study. Another study ${ }^{43}$ investigated 13 patients aged $8-24$ years $(7 \mathrm{M}, 6 \mathrm{~F})$ and compared them to a control group of subjects of similar age and sex (but not weight). The patient group had an elevated REE, but TEE and TEE $\mathrm{kg}^{-1}$ were similar to the values obtained from the control group. It was concluded that in free-living conditions patients with cystic fibrosis compensate for the increase in REE by reducing the energy expenditure associated with voluntary physical activity. Yet another study ${ }^{44}$ examined the effect of genotype on TEE in 25 children with cystic fibrosis aged 6.1-9.5 years. For the patient group as a whole, $\mathrm{BMR} \mathrm{kg}^{-1}$ was significantly higher than the control values, obtained from healthy subjects of similar age, weight and sex ratio as the patient group. BMR, TEE, TEE $\mathrm{kg}^{-1}$ and TEE/BMR were not significantly different from the control values. For the subgroup of children with the FO8 homozygous genotype, TEE, BMR and TEE/BMR were elevated after adjusting for weight.

Overall, it seems that although children with cystic fibrosis may have an increase in BMR, TEE is often not elevated, except in a subgroup of children with a particular genotype. The cause of the elevated BMR is uncertain but it may be due to mild chest infections, increased work of breathing, or some other unknown metabolic defect. Since children with cystic fibrosis commonly have pancreatic insufficiency and malabsorption, the dietary energy intake may have to be increased. However, pancreatic enzyme replacement therapy can reduce the extent of malabsorption considerably.

Energy turnover in children has also been studied in a range of other chronic conditions, including the following:

- Sickle cell disease ${ }^{45}$. Children with a mean age of $11.3 \mathrm{~kg}$ ( $Z$-score -0.8) were compared with a control group with similar mean age but higher weight, weight $Z$-score, and percent fat. Although TEE was lower in patients with sickle cell disease, the difference was not significant, either before or after adjusting for weight. REE was elevated by $11 \%$ in patients with sickle cell (after adjusting for weight), while EEPA was significantly reduced (but only before adjustment for weight).

- Cyanotic congenital heart disease ${ }^{46-49}$. Two studies ${ }^{47}$ used control values from the literature and reported no increase in TEE in children aged 4-36 months. Another study ${ }^{48}$ using control groups of subjects reported a significant increase in TEE and TEE kg ${ }^{-1}$ at 3 months but not at 2 weeks. REE remained normal at both time points. A further study by the same investigators ${ }^{49}$ reported an increase in TEE $\left(\mathrm{kJ} \mathrm{kg}^{-1}\right.$ per day) and ratio of TEE/BMR in 4 month old infants with a ventricular septal defect, compared to a control group of infants of a similar age. They suggested that the energy cost of physical activity may be substantially increased, so that the infants are unable to meet their increased energy demands, with resulting growth retardation.

- Prader Willi syndrome ${ }^{50}$. The study involved obese patients aged 8-24 years. TEE and EEPA are low, compared to another group of obese individuals not 
suffering from the Prader Willi syndrome. BMR was also low, predominantly because of low FFM.

- Rett syndrome ${ }^{51}$. This neurodevelopmental disorder affects only girls and produces involuntary movements and growth retardation. TEE was not found to be increased. Although girls with Rett syndrome (mean age 6.2 years) spent more waking hours in physical activity than the healthy controls of similar age, the repetitive movements were not sufficiently strong to increase TEE.

- Chronic lung disease during dexamethasone treat$m e n t^{52}$. The young infants in this study did not have increased TEE or energy intake.

- Myelodysplasia ${ }^{20}$. In this study involving individuals aged 13-24 years, REE was significantly reduced by $8 \%$ below that predicted by the FAO/WHO/UNU equation for BMR. TEE/REE was also significantly reduced, especially in the non-ambulatory group (1.20 vs. 1.76 (control group) $)^{20}$. The group also had low FFM, REE and TEE compared to the control group.

Apart from occasional exceptions, such as subgroups of patients with cystic fibrosis and some children with congenital heart disease, most chronic conditions do not produce an increase in TEE kg-1, despite a possible increase in BMR. The general situation is analogous to that observed in adults.

\section{Acute diseases in children}

Eighteen children aged 2-16 years with burns (mean age, 7.8 years; weight, $32.2 \mathrm{~kg}$; $60 \pm 23 \%$ body surface area) were studied for 6-7 days beginning on $24 \pm 18$ days postburn $^{53}$. The mean TEE/REE $(n=8)$ was $1.18 \pm 0.17$, and TEE/BMR predicted (Harris Benedict equation) was $1.33 \pm 0.27(n=18)$. TEE was only $6.72 \pm 2.92 \mathrm{MJ} \mathrm{day}^{-1}$. Therefore, as in adults, TEE was not increased (actually decreased) because of the reduction in EEPA.

Another study ${ }^{47}$ measured energy expenditure for 7 days before and 7 days after surgery for congenital heart disease in children aged 7-33 months using the doubly labelled water method. Preoperative values were significantly higher than post-operative values subjects ( 0.49 vs. $0.32 \mathrm{MJ} / \mathrm{kgFFM} /$ day), and similar to those obtained from a control group of subjects $(0.46 \mathrm{MJ} / \mathrm{kgFFM} /$ day $)$, who had similar mean age as the children with disease. Other studies mentioned below used control groups with similar weight, but not similar age, as the patient group.

\section{The limits of physical activity and the effect of exercise on the components of energy turnover in health and disease}

The first section below summarises the extent to which TEE and EEPA can increase in healthy subjects undertaking extreme physical activity, so that it can be contrasted with the extreme inactivity of disease. Under extreme physical exertion TEE can rise up to $25-30 \mathrm{MJday}^{-1}$, which contrasts with disease states, where it usually decreases to 6-12 $\mathrm{MJ} \mathrm{day}^{-1}$. Under extreme physical exertion EEPA can account for up to about $60 \%$ of TEE, in comparison with severe acute diseases, where it may account for $<10 \%$ of TEE. Intermediate values are found in chronic diseases and healthy free-living subjects.

The second section below considers the extent to which the increase in energy expended in exercise is compensated by a reduction in discretionary physical activity in inactive to moderately active subjects. It also considers the extent to which an increase in TEE is associated with a compensatory increase in food intake, which will limit loss of body weight. Studies in disease are unfortunately limited.

\section{The limits of physical activity}

A few doubly labelled water studies have been performed in healthy adults undertaking extreme physical activities ${ }^{54-62}$, such as hard manual work $^{54,55}$, military training $^{56}$, and sports activities ${ }^{57-62}$ (Table 3). In some of these studies energy intake did not match energy expenditure, with the result that subjects were in negative energy balance. In the Mount Everest expedition regional fat mass decreased while muscle mass was spared. The highest energy expenditure was that observed in two Arctic explorers, who had a TEE of over $40 \mathrm{MJ} \mathrm{day}^{-1}$ and PAL values of over four during part of the expedition. Both subjects lost a considerable amount of weight because of limited food supplies (Table 3).

The energy expended in intense agricultural activities or other heavy manual work has been studied in Gambian men, who were reported to have PAL values of 2.4 and 2.97 , respectively ${ }^{54,55}$. The latter value may have been higher than under normal circumstances because financial rewards may have increased work output. However, such high activity levels can also be inferred from other studies, such as those undertaken in lumberjacks, who regularly recorded energy intake of up to about $33 \mathrm{MJ}$ day $^{-63}$.

These studies with high TEE and PAL values (range $\sim 2-4$ ) contrast with the decrease in physical activity observed in acute (PAL values $1 \sim 1.25$ in the early phase) and chronic diseases $(1.25-1.9$, but mostly $<1.5$ in severe diseases). The studies involving adult patients with disease were largely carried out in high income countries, where the control values usually ranged from $\sim 1.4$ to 2.0 (mostly 1.6-1.8). The 'normal' values may be higher in low income countries, at least during periods of active agricultural activities. Five studies ${ }^{54,55,64-66}$ in which PAL values could be calculated from non-pregnant nonlactating adults before supplementation or other interventions, yielded the following mean PAL values: 1.96 (Bolivia $\left.{ }^{64}\right), \quad 1.97$ (Gambia $\left.^{65}\right), \quad 1.87$ (Guatemala $\left.^{66}\right), 2.40$ $\left(\right.$ Gambia $^{55}$; Table 3) and 2.98 (Gambia ${ }^{54}$; Table 3)) (mean $2.31 \pm 0.63 ; n=55$ ). Although the variability in TEE may have a genetic component, much of it is probably environmental since Pima Indians in Arizona (USA) have 


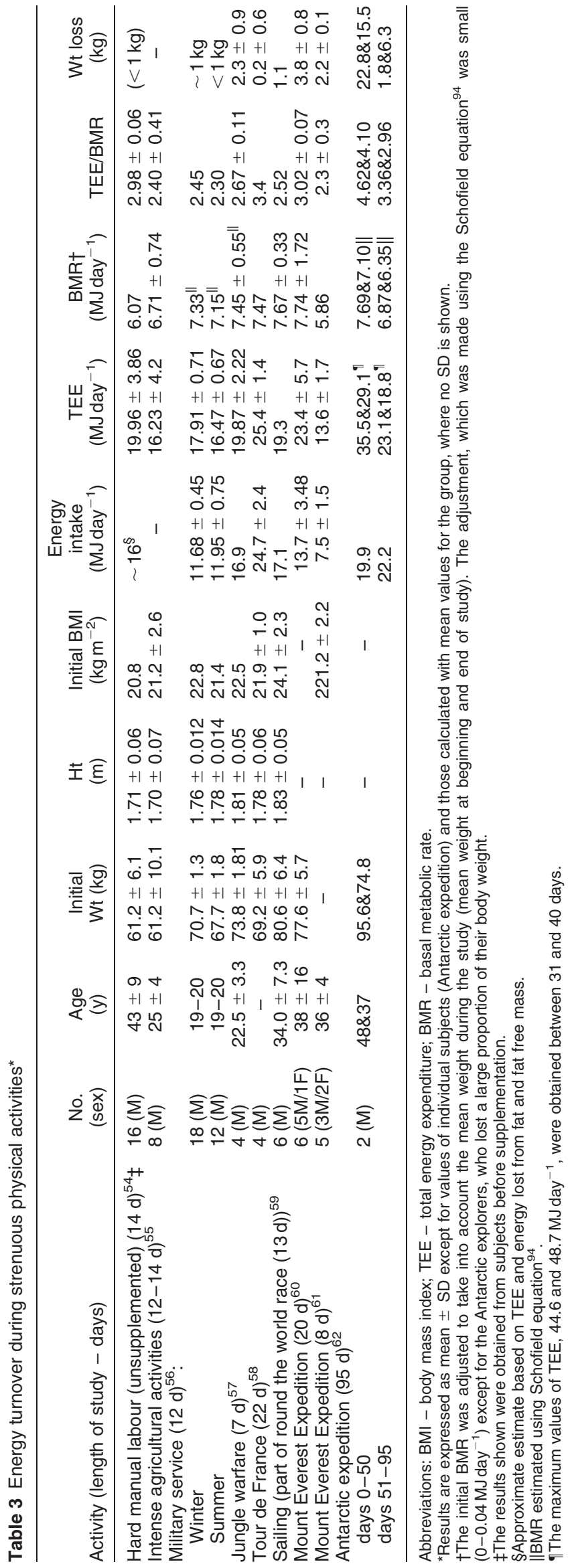


been reported to have much greater PAL values than those in Mexico, where a greater proportion of time is spent on occupational activities (1.57 vs. 1.97$)^{67}$.

\section{The effects of exercise on the components of energy turnover in bealth and in disease}

Despite the large literature on the effect of physical activity and exercise on energy homeostasis, few studies have examined the components of energy turnover in freeliving conditions, or body composition before and after introduction of a training programme that lasts for at least a few weeks. Analysis of such studies can be used to assess the extent to which an increase in energy expenditure induced by exercise is compensated for by decreased discretionary activities between bouts of training, and the extent to which dietary intake compensates for an energy deficit induced by the exercise. To address these issues in healthy subjects an analysis of five studies was undertaken $^{68-72}$ to add to previous assessments ${ }^{69,73}$. Details of the studies are shown in Table 4 . Three studies ${ }^{68,69,71,72}$ involved young to middle aged adults, one involved obese children aged 10-11 years ${ }^{70}$, and one healthy elderly subject $^{72}$. The type of training schedule varied (jogging, cycling, weight training) as did its duration (4-40 weeks). The following emerged from the analysis:

1. TEE expenditure increased in all studies (significant in all studies except the elderly study) and generally to a greater extent in those studies that were associated with a higher energy cost of training. The ratio of TEE to sleeping energy expenditure (or TEE to REE) also increased, except in the elderly study where there was a decrease from 1.51 to 1.40 . Despite these changes there was a significant increase in maximum $\mathrm{O}_{2}$ consumption $\left(\mathrm{VO}_{2} \mathrm{max}\right)$ in the elderly subjects.

2. Basal energy expenditure (BEE; sleeping or REE) did not change, except in the elderly study, where there was a $10 \%$ increase in REE, for unknown reasons.

3. None of the studies, except the elderly study, showed a reduction in the energy cost of discretionary or voluntary activities, which took place between exercise schedules (i.e. the training added to rather than replaced the energy cost of physical activity).

4. Energy intake increased in all studies, apart from the elderly study, corresponding to $\sim 50-80 \%$ of the increase in TEE. In the elderly study a small reduction in energy intake $\left(\sim 0.3 \mathrm{MJ} \mathrm{day}^{-1}\right)$ accompanied a small increase in TEE $\left(0.27 \mathrm{MJ} \mathrm{day}^{-1}\right)$.

5. Body weight was typically unaltered. Although the mean change was within the range +0.5 to $-0.9 \mathrm{~kg}$, this resulted from a decrease in fat mass $(-0.04$ to $-0.9 \mathrm{~kg})$ and an increase in FFM ( +0.8 to $+2.1 \mathrm{~kg})$.

From these studies it is suggested that a change in body weight is not a good indicator of changes in energy balance, because a reduction in fat mass is compensated by an increase in FFM, which is most likely to be due to an increase in muscle bulk. The changes in TEE induced by the training were not large $\left(0.3-2.8 \mathrm{MJ} \mathrm{day}^{-1}\right)$ despite adding to and not replacing the energy cost of routine physical activities. A compensatory increase in dietary intake (generally corresponding to a $50-75 \%$ increase in TEE) is likely to have limited the negative energy balance which was associated with a total mean loss of $<1 \mathrm{~kg}$ of body fat during the period of training ( $4-40$ weeks). The time course of these compensatory changes is unknown. The results of the elderly study ${ }^{72}$ are generally different from the other studies and therefore it is necessary to confirm or refute the observations using a different cohort of patients. A more recent study ${ }^{74}$ involving resistance training for 26 weeks in older adults aged 61-77 years is at variance with the findings cited here ${ }^{72}$. They showed a significant increase in TEE and a borderline significant increase (not decrease) in the energy expended in nontraining physical activity. There is little information on the effects of exercise training in patients with disease.

However, a study in patients with heart failure ${ }^{75}$ reported no increase in TEE following an exercise programme, presumably because of a reduction in discretionary activities. It is difficult to generalise on the basis of this study. There is a need to establish similar information in other diseases and consider the effects of age and obesity.

\section{Some general perspectives on energy requirements}

The analysis presented in this paper has focused on recent studies that have measured TEE using tracer methods (doubly labelled water and bicarbonate urea) and 24-hour continuous indirect calorimetry in patients with a range of conditions: infective, degenerative, malignant, traumatic, congenital and others. TEE is usually normal or reduced, partly because of a reduction in body weight and FFM (disease-related malnutrition or neurological causes of wasting), and partly because of reduced physical activity. The reduced physical activity compensates for any increase in BMR, which is common in acute diseases. There are some exceptions, such as subgroups of patients with cystic fibrosis, anorexia nervosa, and congenital heart disease, where TEE has been reported to be increased. Such patients are often underweight, and therefore weight adjustments are necessary to demonstrate differences compared to control groups. Without such adjustments, TEE is again typically not increased.

In making recommendations about energy requirements in disease there is a need to consider not only the energy required to maintain energy balance, but also the energy required to change body composition at different rates in both under-nourished and over-nourished patients. This paper did not consider energy turnover in overweight and obese individuals. It also did not consider the extent of malabsorption, which may complicate a 


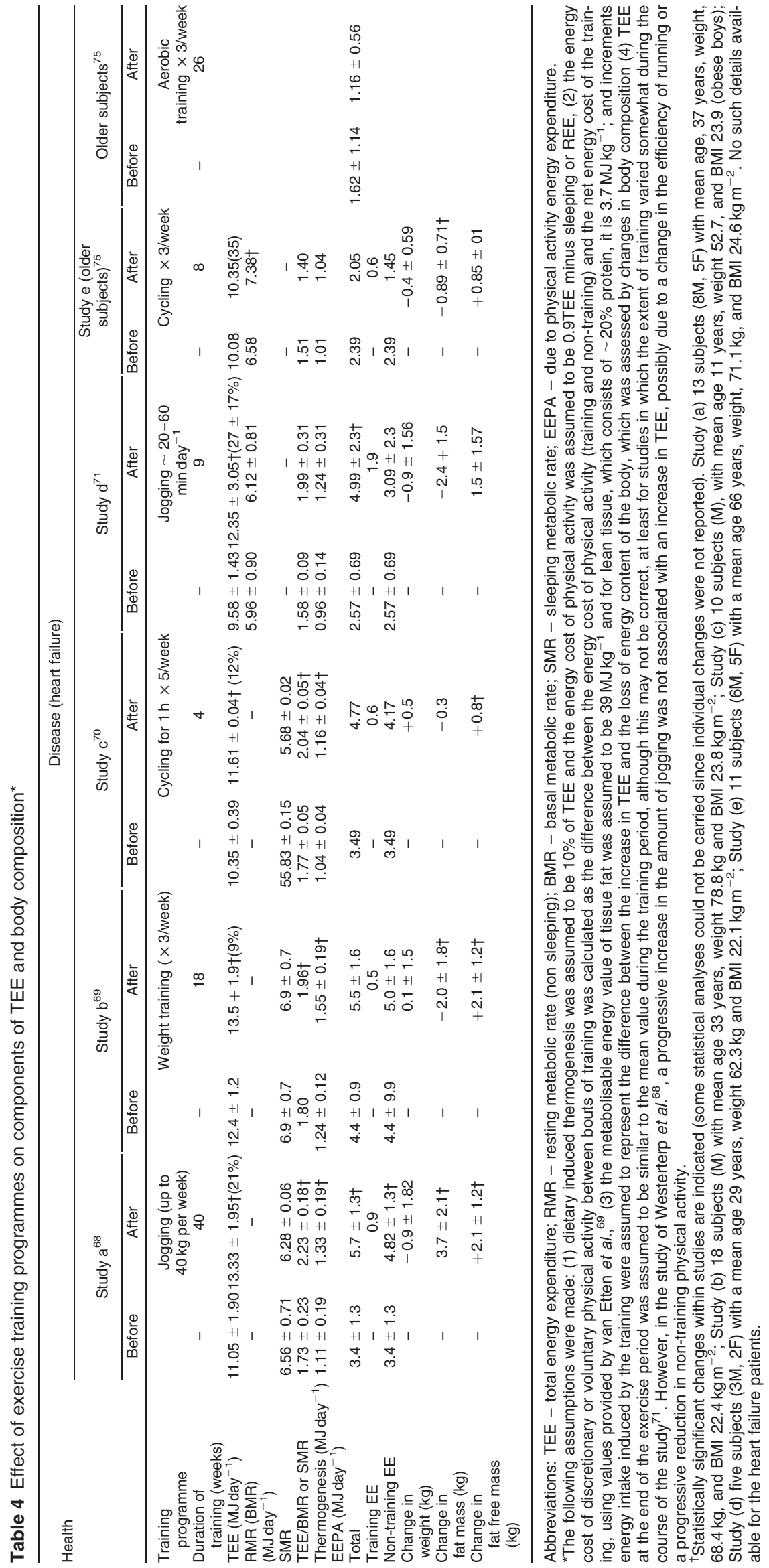


variety of diseases. Recommendations about the rate of repletion were also not considered here.

The lack of accurate information on TEE in a large number of diseases, does not allow a comprehensive assessment of the field, especially in low income countries, where the type of diseases and their treatment differ from high income countries. Therefore, any recommendations about energy requirements should take into account alternative approaches to those presented in this paper, including clinical perspectives. The extent to which disease-related malnutrition should be treated (especially when it is a consequence of incurable disease) can be controversial, and attitudes may vary in different countries.

The distinction between health and disease is not always clear cut. For example, growth failure is common in low income countries and may persist despite adequate availability of food. The frequent presence of an acute phase response ${ }^{8}$, including elevated circulating concentrations of acute phase proteins, cytokines, immunoglobulins, and cortisol, suggests that there is an underlying inflammatory condition. For example, about a quarter of children in developing countries have elevated acute phase proteins and circulating cytokines, and these may occur in the absence of overt signs of disease ${ }^{8}$. The boundaries between health and disease need to be defined because dietary energy and protein recommendations may depend on the presence or absence of disease/inflammatory conditions.

The proportion of older individuals in the population is increasing in both low income and high income countries. The incidence of many diseases and disabilities also increases with age $^{32}$. For example, in the UK 39\% of individuals aged $65-74$ years and $48 \%$ of those over 75 years have a long-standing illness limiting activity ${ }^{7}$. If nutritional recommendations are provided only for healthy individuals, they will miss large segments of the older population.

Although tracer methods for measuring energy expenditure in free-living conditions have provided valuable information about energy requirements in health and disease, most studies have not involved a random selection of subjects. This raises the possibility of biased results for both patients/control groups. The same criticism can be raised against most tracer studies assessing 'normal' TEE in health. Therefore, complementary alternative studies involving a random selection of subjects should be considered.

\section{References}

1 Macallan DC, Noble C, Baldwin C, Jebb SA, Prentice AM, Coward WA, Sawyer MB, McManus TJ, Griffin GE. Energy expenditure and wasting in human immunodeficiency virus infection. New England Journal of Medicine 1995; 333: 83-8.

2 Paton NIJ, Elia M, Jebb SA, Jennings G, Macallan DC, Griffin
GE. Total energy expenditure and physical activity measured with the bicarbonate-urea method in patients with human immunodeficiency virus infection. Clinical Science 1996; 91: $241-5$.

3 Heijlingenberg R, Romjin JA, Westerterp KR, Jonkers CF, Prins JM, Sauerwein HP. Total energy expenditure in human immunodeficiency virus-infected man and healthy controls. Metabolism 1997; 46: 1324-6.

4 Selberg O, Coors M, Trimborn P, Ockenga J, Muller MJ, Suttmann U. Energy balance in stable human immunodeficiency virus infected patients: q doubly labelled water study. Clinical Nutrition 2000; 19(Suppl. 1): (Abs)1.

5 Johann-Liang R, O'Neill L, Cervia J, Haller I, Giunta Y, Licholai T, Noel, Gary J. Energy balance, viral burden insulin-like growth factor-1, interleukin-6 and growth impairment in children infected with human immunodeficiency virus. AIDS 2000; 14: 683-90.

6 Arpadi SM, Cuff PA, Kotler DP, Wang J, Bamji M, Lange M, Pierson RN, Matthews DE. Growth velocity, fat-free mass and energy intake are inversely related to viral load in HIVinfected children. Journal of Nutrition 2000; 130: 2498-502.

7 Bennet N, Jarvis L, Rowlands O, Singleton N, Haselden L. Living in Britain. Results of the 1994 General Household Survey. Office of Population Censuses and Surveys, Social Survey Division, Her Majecsty's Stationery Office, London, 1996.

8 Solomons N, Mazariegos M, Brown KH, Klassing K. The underprivileged developing country child: environmental contamination and growth failure revisited. Nutrition Reviews 1993; 51: 327-32.

9 Elia M, Jebb SA. Changing concepts of energy requirements in critically ill patients. Current Medical Literature Clinical Nutrition 1992; 1: 35-8.

10 Elia M. Changing concepts of nutrient requirements in disease: implications for artificial nutritional support. Lancet 1995; 345: 1279-84.

11 Eddy TP, Nicholson AL, Wheeler EF. Dietary requirements in cerebral palsy. Developmental Medicine and Child Neurology 1965; 7: 377-86.

12 Phelps WM. Dietary requirements in cerebral palsy. Journal of the American Dietetic Association 1951; 27: 869-70.

13 Elia M, Jones MG, Jennings G, Poppitt SD, Fuller NJ, Murgatroyd PR, Jebb SA. Estimation of energy expenditure from specific activity of urine urea during lengthy subcutaneous $\mathrm{NaH}^{14} \mathrm{CO}_{3}$ infusion. American Journal of Physiology 1995; 269: E172-82.

14 Gibney E, Elia M, Jebb SA, Murgatroyd P, Jennings G. Total energy expenditure in patients with small cell lung cancer: results of a validated study using the bicarbonate-urea method. Metabolism 1996; 46: 1412-17.

15 Paton NIJ, Angus B, Chaowagul W, Simpson AJ, Suputtamonkol M, Calder G, Milne E, White NJ, Griffin GE. Protein and energy metabolism in chronic bacterial infections: studies with melioidosis. Clinical Science 2001; 100: $101-10$.

16 Gardner AW, Poelman ET. Assessment of free-living daily physical activity in older claudicants: validation against the doubly labelled water method. Journal of Gerontology 1998; 53A: M275-80.

17 Kramer JA, Dewit O, Elia M. Relationship between physical activity level, performance status, and quality of life in patients with inoperable lung cancer. Proceeding of the Nutrition Society 1998; 57: 109A.

18 Elmstahl S. Energy expenditure, energy intake and body composition in geriatric long-stay patients. Comprehensive Gerontology 1987A; 1(3): 118-25.

19 van den Berg-Emons R, Saris WHM, Westerterp KR, van Baak MA. Heart rate monitoring to assess energy expenditure in children with reduced physical activity. Medicine and Science in Sports and Exercise 1996; 28: 496-501. 
20 Bandini LG, Schoeller DA, Fugakawa NK, Wykes LJ, Dietz WH. Body composition and energy expenditure in adolescents with cerebral palsy or myelodysplasia. Pediatric Research 1991; 29: 70-9.

21 Kinney JM, Lang CL, Gump FE, Duke JH. Tissue composition of weight loss in surgical patients I elective operation. Annals of Surgery 1968; 168: 459-74.

22 Royall D, Fairfolm L, Peters WJ, Jeejeebohy KN, Allard JP. Continuous measurement of energy expenditure in ventilated burn patients: an analysis. Critical Care Medicine 1994; 22: 399-406.

23 Welsh FA, Ginsberg MD, Reider W, Budd WW. Deleterious effect of glucose pretreatment on recovery from diffuse cerebral ischemia in the cat. II. Regional metabolic levels. Stroke 1980; 11: 355-63.

24 Murray MJ, Murray AB. Anorexia as method of host defence. American Journal of Clinical Nutrition 1979; 32: 593-6.

25 Brooks M, Melnik G. The refeeding syndrome. An approach to undertaking its complications and preventing its recurrence. Pharmacotherapy 1995; 15: 713-26.

26 Solomon SM, Kirby DF. The refeeding syndrome: a review. Journal of Parenteral and Enteral Nutrition 1990; 14: 90-7.

27 Elia M, Livesey G. Energy expenditure and fuel selection in biological systems: the theory and practice of calculations based on indirect calorimetry and tracer methods. World Review of Nutrition and Dietetics 1992; 70: 68-131.

28 Kinney JM, Long CL, Gump JH, Duke JH. Tissue composition of weight loss in surgical patients I. Elective operation. Annals of Surgery 1968; 168: 459-74.

29 Gibney E, Jebb SA, Jennings G, Murgatroyd PR, Elia M. Measurement of total energy expenditure in patients with lung cancer and validation of the bicarbonate urea method against whole body indirect calorimetry. Proceedings of the Nutrition Society 1997; 56: 226A.

30 Elia $M$. Tissue distribution and energetics in weigh loss and undernutrition. In: Kinney JM, Tucker HN, eds. Physiology, Stress and Malnutrition: Functional Correlates and Nutritional Intervention. New York: Lipcott-Raven, 1997.

31 Elia M. Organ and tissue contribution to metabolic rate. In: Kinney JM, Tucker HN, eds. Energy Metabolism: Tissue Determinants and Cellular Corollaries. New York: Raven Press, 1992, 61-79.

32 Elia M, Ritz P, Stubbs RJ. Energy expenditure in the elderly. European Journal of Clinical Nutrition 2000; 54(Suppl. 3): S92-103.

33 Paton NIJ, Elia M, Jebb SA, Jennings G, Macallan DC, Griffin GE. Measurements of total energy expenditure in patients with human immunodeficiency virus infection using the bicarbonate urea method. Proceedings of the Nutrition Society 1996; 55: 154A.

34 Valencia ME, McNeill G, Haggarty P, Moya SY, Pinelli A, Quihui L, Davalos R. Energetic consequences of mild Giardiasis instestinalis infestationin Mexican children. American Journal of Clinical Nutrrition 1995; 61: 860-5.

35 Casper RC, Schoeller DA, Kushner R, Hnilicka J, Gold ST. Total daily energy expenditure and activity level in anorexia nervosa. American Journal of Clinical Nutrition 1991; 53: $1143-50$.

36 van Marken Lichtenbelt WD, Heidendal GAK, Westerterp KR. Energy expenditure and physical activity in relation to bone mineral density in women with anorexia nervosa. European Journal of Clinical Nutrition 1997; 51: 826-30.

37 Bessey PQ, Wilmore DW. The burned patient. In: Kinney JM, Jeejeebhoy KN, Hill GL, Owen OE, eds. Nutrition and Metabolism in Patient Care. London: W.B. Saunders, 1988; 672-700.

38 Elia M. Hunger disease: Metabolic response to starvation, injury and sepsis. Clinical Nutrition 2000; 19: 379-86.

39 Stallings VA, Zemel BS, Davies JC, Cronk CE, Charney EB. Energy expenditure of children and adolescents with severe disabilities: a cerebral palsy model. American Journal of Clinical Nutrition 1994; 64: 627-34.

40 WHO. Energy and Protein Requirements. Report of a Joint FAO/WHO/UNU Expert Consultation. Technical Report Series No. 724. Geneva: World Health Organization, 1985.

41 Johnson RK, Hildreth HG, Contompasis SH, Goran MI. Total energy expenditure in adults with cerebral palsy as assessed by doubly labelled water. Journal of the American Dietetic Association 1997; 97: 966-70.

42 Shepherd RW, Vasquez-Velasquez L, Prentice A, Holt TL, Coward WA, Lucas A. Increased energy expenditure in young children with cystic fibrosis. Lancet 1988; I: 1300-3.

43 Spicher V, Roulet M, Schulz Y. Assessment of total energy expenditure in free-living patients with cystic fibrosis. Journal of Pediatrics 1991; 118: 865-72.

44 Tomezsko JL, Stallings VA, Kawchak DA, Goin JE, Diamond G, Scanlin TF. Energy expenditure and genotype of children with cystic fibrosis. Pediatrics 1994; 35: 451-60.

45 Barden EM, Zemel BS, Kawchak DA, Goran MI, OheneFrempong K, Stallings V. Total and resting energy expenditure in children with sicklecell disease. Journal of Pediatrics 2000; 136: 73-9.

46 Barton J, Hindmarsh P, Scrimgeour C, Rennie M, Preece M. Energy expenditure in congenital heart disease. Archives of Diseases of Children 1994; 70: 5-9.

47 Mitchel P, Davies P, Day P, Pollock J, Jamieson M, Wheatley D. Energy expenditure in children with congenital heart disease before and after cardiac surgery. Journal of Thoracic and Cardiovascular Surgery 1994; 107: 374-80.

48 Leitch CA, Karn CA, Peppard RJ, Granger D, Leichty EA, Ensing GL, Denne SC. Increased energy expenditure in infants with cyanotic congenital heart disease. Journal of Pediatrics 1998; 133: 755-60.

49 Ackerman IL, Karn CA, Denne SC, Ensing GJ, Leitch CA. Total but not resting energy expenditure is increased in infants with ventricular septal defect. Pediatrics 1998; 102: $1172-7$.

50 Schoeller D, Levitsky LL, Bandini LG, Dietz WW, Walczak A. Energy expenditure and body compositionin Prader-Willi syndrome. Metabolism 1988; 37: 115-20.

51 Motil KJ, Schultz RJ, Wong WW, Glaze DG. Increased energy expenditure associated with repetitive involuntary movement does not contribute to growth failure in girls with Rett syndrome. Journal of Pediatrics 1998; 132: 228-32.

52 Leitch CA, Ahlrichs J, Karn C, Denne SC. Energy expenditure and energy intake during dexamethasone therapy for chronic lung disease. Pediatric Research 1999; 46: 109-13.

53 Goran MI, Peters EJ, Herndon DN, Wolfe RR. Total energy expenditure in burned children using doubly labelled water technique. American Journal of Physiology 1990; 259: E576-85.

54 Diaz E, Goldberg GR, Taylor M, Savage JM, Sellen D, Coward WA, Prentice AM. Effect of dietary supplementation on work performance in Gambian labourers. American Journal of Clinical Nutrition 1991; 53: 803-11.

55 Heini AF, Minghelli G, Diaz E, Prentice AM, Schutz Y. Freeliving energy expenditure assessed by two different methods in rural Gambian men. European Journal of Clinical Nutrition 1996; 50: 284-9.

56 Burstein R, Coward AW, Askew WA, Carmel K, Irving C, Shpilberg O, Moran D, Pikarsky A, Grinot G, Sawyer M, Golan R, Epstein Y. Energy expenditure variations in soldiers performing military activities under cold and hot climate conditions. Military Medicine 1996; 161: 750-4.

57 Forbes-Ewan CH, Morrissey BLL, Gregg GC, Waters DR. Use of doubly labelled water technique in soldiers training for jungle warfare. Journal of Applied Physiology 1989; 67: 14-8.

58 Saris W. Limits of human endurance: lessons from the Tour de France. In: Kinney JM, Tucker HN, eds. Physiology, Stress and Malnutrition: Functional Correlates, Nutritional 
Intervention. New York: Lippincott-Raven Publishers, 1997, 451-62.

59 Branth S, Hambraeus L, Westerterp K, Andersson A, Edsgren R, Mustelin M, Nilsson R. Energy turnover in a sailing crew during offshore racing around the world. Medicine and Science in Sports and Exercise 1996; 28: 1272-6.

60 Reynolds RD, Lickteig JA, Deuster PA, Howard MP, Conway JM, Pietersma A, deStoppelaar J, Deurenberg P. Energy metabolism increases and regional body fat decreases while regional muscle mass is spared in humans climbing Mt. Everest. Journal of Nutrition 1999; 129: 1307-14.

61 Westerterp KR, Kayser B, Brouns F, Herry JP, Saris WHM. Energy expenditure climbing Mt. Everest. Journal of Applied Physiology 1992; 73: 1815-9

62 Stroud MA. Thermoregulation, exercise, and nutrition in the cold: investigations on a polar expedition. In: Kinney JM, Tucker HN, eds. Physiology, Stress, and Malnutrition: Functional Correlates, Nutritional Intervention. New York: Lippincott-Raven Publishers, 1997; 531-48.

63 Wood CD, Mansfield ER. Studies of the Food of Maine Lumbermen. Bulletin no. 149. Washington, DC: US Department of Agriculture, 1904.

64 Kashiwazaki H, Dejima Y, Orias-Rivera J, Coward WA Energy expenditure determined by the doubly labelled water method in Bolivian Arymara living in a high altitude agro-pastoral community. American Journal of Clinical Nutrition 1995; 62: 901-10.

65 Singh J, Prentice AM, Diaz E, Coward WA, Ashford JA, Sawyer M, Whitehead R. Energy expenditure of Gambian women during peak agricultural activity measured by the doubly labelled water method. British Journal of Nutrition 1989; 62: 315-29.

66 Stein TP, Johnston FE, Greiner L. Energy expenditure and socioeconomic status in Guatemala as measured by the doubly labelled water method. American Journal of Clinical Nutrition 1988; 47: 196-200.

67 Esparza J, Fox C, Harper IT, Bennett PH, Schulz LO, Valencia ME, Ravussin E. Daily energy expenditure in Mexican and USA Pima Indians: low physical activity as a cause of obesity. International Journal of Obesity 2000; 24: 55-9.

68 Westerterp KR, Meijer GA, Janssen EME, Saris WHM, Hoor FT. Long-term effect of physical activity on energy balance and body composition. British Journal of Nutrition 1992; 68 $21-30$.

69 van Etten MLA, Westerterp KR, Verstappen FTJ, Boon BJB, Saris WHM. Effect of an 18-wk weight-training program on energy expenditure and physical activity. Journal of Applied Physiology 1997; 82: 298-304.

70 Blaak EE, Westerterp KR, Bar-Or O, Wouters LJ, Saris WH. Total energy expenditure and spontaneous activity in relation to training in obese boys. American Journal of Clinical Nutrition 1992; 55: 777-82.

71 Bingham SA, Goldberg GR, Coward WA, Prentice AM, Cummings JH. The effect of exercise and improved physical fitness on basal metabolic rate. British Journal of Nutrition 1989; 61: 155-73.

72 Goran MI, Poelman ET. Endurance training does not enhance total energy expenditure in healthy elderly persons. American Journal of Physiology 1992; 263: E950-7.

73 Westerterp KR. Alterations of energy balance with exercise. American Journal of Clinical Nutrition 1998; 68(Suppl. 1): S970-S4.

74 Hunter GR, Wetzstein GJ, Fields DA, Brown A, Bamman MM. Resistance training increases total energy expenditure and free-living physical activity in older adults. Journal of Applied Physiology 2000; 87: 977-84.

75 Gottlieb SS, Fisher ML, Freudenberger R, Robinson S, Zietowski G, Alves L, Krichten C, Vaitkevicus P, McCarter R. Effects of exercise training on peak performance and quality of life in congestive heart failure patients. Journal of Cardiac Failure 1999; 5: 188-94.

76 Gardner AW, Womack CJ, Sieminski DJ, Montgomery PS, Killewich LA, Fonong T. Relationship between free-living daily physical activity and ambulatory measures in older claudicants. Angiology 1998; 49: 327-37.

77 Gardner AW, Killewich LA, Katzel LI, Womack CJ, Montgomery PS, Otis RB, Fonong T. Relationship between free-living daily physical activity and peripheral circulation in patients with intermittent claudication. Angiology 1999; 50: 289-97.

78 Otis RB, Brown AS, Womack CJ, Fonong T, Gardner AW. Relationship between physical activity recall and free-living daily physical activity. Angiology 2000; 51: 181-8.

79 Toth MJ, Gottlieb SS, Fisher ML, Poelman ET. Daily energy expenditure in heart failure patients. Metabolism 1997; 46: 1294-8.

80 Poelman ET. Special considerations in design of trials with elderly subjects: unexplained weight loss, body composition and energy expenditure. Journal of Nutrition 1999; 129: S260-S3.

81 Poelman ET, Toth MJ, Goran MI, Carpenter WH, Newsholme $\mathrm{P}$, Rosen CJ. Daily energy expenditure in free-living noninstitutionalised Alzheimer's patients. Neurology 1997; 48: 997-1002.

82 Poelman ET, Dvorak R. Energy expenditure, energy intake, and weight loss in Alzheimer's disease. American Journal of Clinical Nutrition 2000; 71(Suppl.): S650-S5.

83 Dvorak RV, Poelman ET. Appendicular skeletal musclemass, physical activity, and cognitive status in patients with Alzheimer's disease. Neurology 1998; 51: 1386-90.

84 Toth MJ, Fishman PS, Poelman ET. Free-living daily energy expenditure in patients with Parkinson's disease. Neurology 1997; 48: 88-91.

85 Pratley R, Salbe AD, Ravussin E, Caviness JN. Higher sedentary energy expenditure in patients with Huntington's disease. Annals of Neurology 2000; 47: 64-70.

86 Pullicino E, Coward A, Elia M. Total energy expenditure in intravenously fed patients measured by the doubly labelled water technique. Metabolism 1993; 42: 58-64.

87 Schoeller DA, Kushner RF, Jones PJH. Validation of doubly labelled water for measuring energy expenditure during parenteral nutrition. American Journal of Clinical Nutrition 1986; 44: 291-8.

88 Kushner RF, Schoeller DA. Resting and total energy expenditure in patients with inflammatory bowel disease. American Journal of Clinical Nutrition 1991; 53: 161-5.

89 Carlsson M, Nordenstrom J, Hedenstierna G. Clinical implications of continuous measurement of energy expenditure in mechanically ventilated patients. Clinical Nutrition 1984; 3: 103-10.

90 Weekes E, Elia M. Observations on the patterns of 24 hour energy expenditure and changes in body composition and gastric emptying in head injured patients. Journal of Parenteral and Enteral Nutrition 1996; 20: 31-7.

91 Wall-Alonso E, Schoeller DA, Schechter L, Gottlieb LJ. Measured total energy requirements of adult patients with burns. Journal of Burn Care and Rehabilitation 1999; 20: 329-37.

92 Novick WM, Nusbaum M, Stein TP. The energy costs of surgery as measured by the doubly labelled water (2H218O) method. Surgery 1988; 103: 99-105.

93 Taggart DP, McMillan DC, Preston C, Richardson R, Burns RJG, Wheatley DJ. Effects of cardiac surgery and intraoperative hypothermia on energy expenditure as measured by doubly labelled water. British Journal of Surgery 1991; 78: 237-41.

94 Schofield WN, Schofield C, James WPT. Basal Metabolic Rate. Human Nutrition: Clinical Nutrition 1985; 39(C): 1-96.

95 Elia M. Artificial feeding: requirements and complications. Medicine International 1994; 22: 411-5. 